\title{
Anomalous temperature changes in the UTLS region prior to the 2008 Nura Earthquake
}

\author{
Leonid Sverdlik ${ }^{1, *}$ \\ ${ }^{1}$ Research Station of the Russian Academy of Sciences in Bishkek, Kyrgyzstan
}

\begin{abstract}
The paper presents results of retrospective analysis of satellite temperature time series above the epicentral area of the destructive Nura earthquake of $\mathrm{M}=6.7$, occurred in a seismically active Tien-Shan region on October 5, 2008. An algorithm based on the use of a modified STA/LTA criterion has been developed for the purpose of selection and identification of perturbations associated with seismic activity. It has been established that an explicit mesoscale temperature anomaly in the upper troposphere and lower stratosphere (UTLS) was observed during the period from October 1 to 3, 2008. Temporal and spatial distributions of the temperature perturbations consistently appeared at various UTLS levels suggest probable association with seismic event preparation.
\end{abstract}

\section{Introduction}

Exploration of thermal anomalies on the Earth surface and in the atmosphere is one of the most promising line of research aimed at establishment of possible connection with seismic activity [1]. Experiments carried out in various geographic regions using satellite data confirmed occurrence of thermal effects before strong earthquakes and their potency to serve as an indicator of tectonic activity [2]. Exploration of processes of interaction between various atmospheric layers and the lithosphere taking place under conditions of strong spatial-temporal variability of the vertical atmosphere temperature structure is both complicated and critical task. It determines the importance of development of effective ways of identification of anomalous variations in temperature changes. In recent decades scientists have achieved a great progress in remote sensing data processing, interpretation of origin atmospheric perturbations origin and development of physical models demonstrating connection between the anomalies and earthquake occurrence [3]. One can mention results of numerous researches in earthquake-prone regions using RST-based (Robust Satellite Techniques) methods [1] and more complex versions of this method to identify pre-seismic anomalies [4].

The algorithm presented in this article based on use of the known STA/LTA (Short Time Average / Long Time Average) criterion that has become a frequent practice of identification of pulsewise oscillations, in particular, recognizing seismic wave arrival and registration of microseismic events [5] may be considered to be one of promising, methods to identify

* Corresponding author: 1.sverdlik@mail.ru 
anomalies in remote sensing data. Being slightly modified this criterion may be applied to satellite measurements of temperatures.

This study presents an analysis of spatial-temporal temperature variations in the upper troposphere and lower stratosphere (UTLS). Through the example of the Nura destructive earthquake of $\mathrm{M}=6.7$ results of identification of anomalous temperature perturbations associated with seismic activity were demonstrated.

\section{Seismic and satellite measurements data}

The Nura destructive earthquake of $\mathrm{M}=6.7\left(39.52^{\circ} \mathrm{N} ; 73.77^{\circ} \mathrm{E}\right)$ occurred in the Southern part of Kyrgyzstan at the depth of $\sim 27.5 \mathrm{~km}$ on October 5, 2008 (15:52:49 UTC) [6]. In total throughout the day more than 50 aftershocks of magnitude $\mathrm{M}=3.0$ concentrated near the epicenter of the main earthquake were registered. (Fig. 1a). Concussions covered a vast territory including border areas of Kyrgyzstan, Tajikistan and China. Figure $1 \mathrm{~b}$ shows the median estimates of peak acceleration as a function of distance [6].
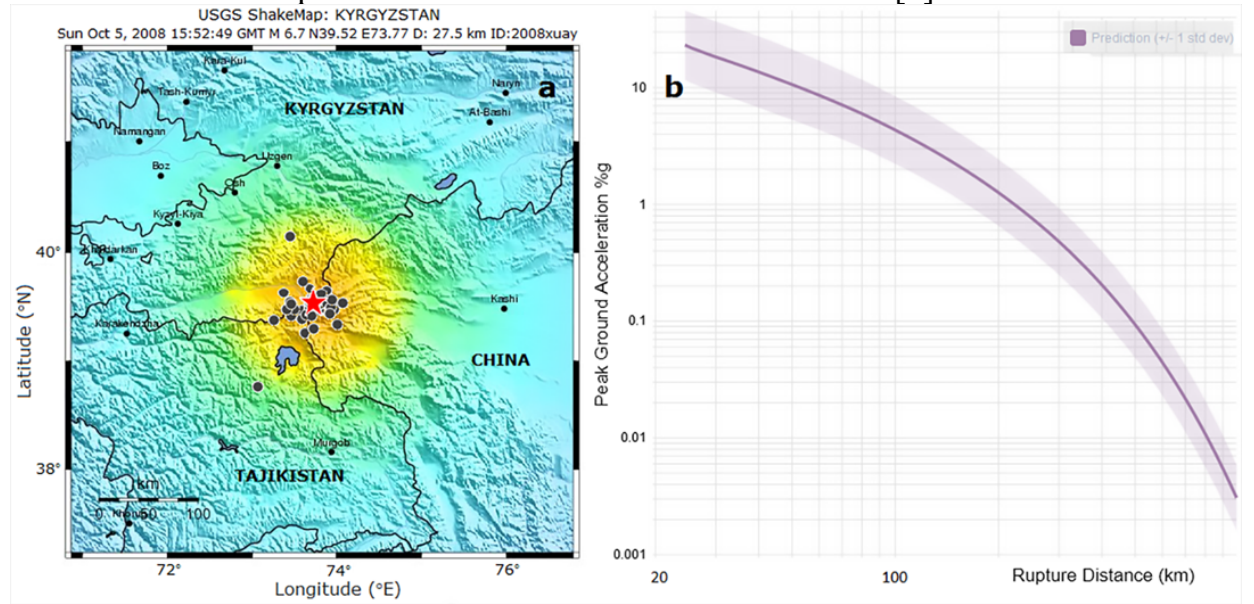

Fig. 1. Aftershock earthquake field $M=6.7$ (05.10.2008) (a) and distribution of Peak Ground Acceleration in \%g (b)

Information of atmosphere temperature changes was obtained from GMAO's ModernEra Retrospective Analysis for Research and Applications (MERRA-2) [7]. The analyzed set of atmosphere temperature temporal and altitude variations at 12 standard isobaric levels $\left(\mathrm{p}_{\mathrm{k}}\right)$ from 500 to $40 \mathrm{hPa}$ covered the upper troposphere and lower stratosphere (UTLS). Satellite data presented temperature values in points of uniform grid $0.5^{\circ} \times 0.625^{\circ}$ and they were restored above the section limited by $35-50^{\circ} \mathrm{N}$ and $60-90^{\circ} \mathrm{E}$ for the temporary period from January through December 2008. The temperature data time discretization $\mathrm{T}(\mathrm{t})$ was $\Delta \mathrm{t}=3 \mathrm{~h}$.

\section{Satellite measurements processing algorithm}

Identification of UTLS temperature perturbations associated with seismic activity was carried out using the algorithm based on analysis of characteristic functions in short (STA) and long (LTA) time windows. On the basis of comparison between seismic activity data and behaviors of temperature time series $T\left(t_{i}\right)$ in UTLS the choice was made in favor of the variance (VAR) which was used as a characteristic function. In this case effectiveness of the algorithm was obviously higher. Calculation of variance ratio $(\mathrm{R})$ was performed for each specific time $t_{i}$ of temperature data at isobaric levels $\left(p_{k}\right)$ : 


$$
R\left(t_{i}, p_{k}\right)=\frac{V A R_{S T A}\left(t_{i}, p_{k}\right)}{V A R_{L T A}\left(t_{i}, p_{k}\right)}
$$

Identification of temperature perturbations was based on calculation of anomality value $\delta \mathrm{T}\left(\mathrm{t}_{\mathrm{i}}\right)$ equal to multiplication of two ratios $\left(\mathrm{R}_{\mathrm{UT}}\right.$ and $\left.\mathrm{R}_{\mathrm{LS}}\right)$ calculated for temperature time series at isobaric levels in the upper troposphere $\left(\mathrm{P}_{\mathrm{UT}}\right)$ and lower stratosphere $\left(\mathrm{P}_{\mathrm{LS}}\right)$. This twoparameter approach allowed to make the algorithm more proof against various non-seismic factors:

$$
\delta T\left(t_{i}\right)=R_{U T}\left(t_{i}, p_{U T}\right) \times R_{L S}\left(t_{i}, p_{L S}\right) \geq T H R
$$

The THR threshold value was established as equal to approximately one standard deviation of the temperature time series being analyzed.

To minimize the probability of forming «false» (in-phase) anomalies parameter $\delta \mathrm{T}_{\mathrm{C}}$ was calculated with account for correlation coefficient $r\left(t_{i}\right)$ between temperature changes at the involved isobaric levels in each short time window (STA):

$$
\delta T_{C}\left(t_{i}\right)=\left\{\begin{array}{l}
0,000_{-} i f_{-} r\left(t_{i}\right)_{S T A} \geq 0 \\
\delta T\left(t_{i}\right) \times\left|r\left(t_{i}\right)_{S T A}\right|_{-} \text {if } r\left(t_{i}\right)_{S T A}<0
\end{array}\right.
$$

Values of moving variances in the short window $\left(\mathrm{VAR}_{\mathrm{STA}}\right)$ described local temperature changes occurred during previous 2.5-3.0 days. This value of the window corresponds with the semiperiod range where, where seismo-atmospheric perturbations are assumed to be dominating other sources that determinate temperature changes [5]. Moving variances in the long window $\left(\mathrm{VAR}_{\mathrm{LTA}}\right)$ were calculated according to values of previous 15 days.

Selection of informative layers in the upper troposphere (UT) and lower stratosphere (LS) was made with account for specifics of dynamics of the vertical temperature structure. Examples of vertical profiles of original data (Fig. 2a), of normalized anomalies (Fig. 2b) and variances of temperature fluctuations in the short time window (Fig. 2c) demonstrate that before the Nura earthquake (October 1 through 03, 2008) the most intensive antiphasic temperature changes occurred at isobaric levels $200 \mathrm{hPa}(\sim 12 \mathrm{~km})$ and $100 \mathrm{hPa}(\sim 17 \mathrm{~km})$. These levels were used to detect pre-seismic perturbations.
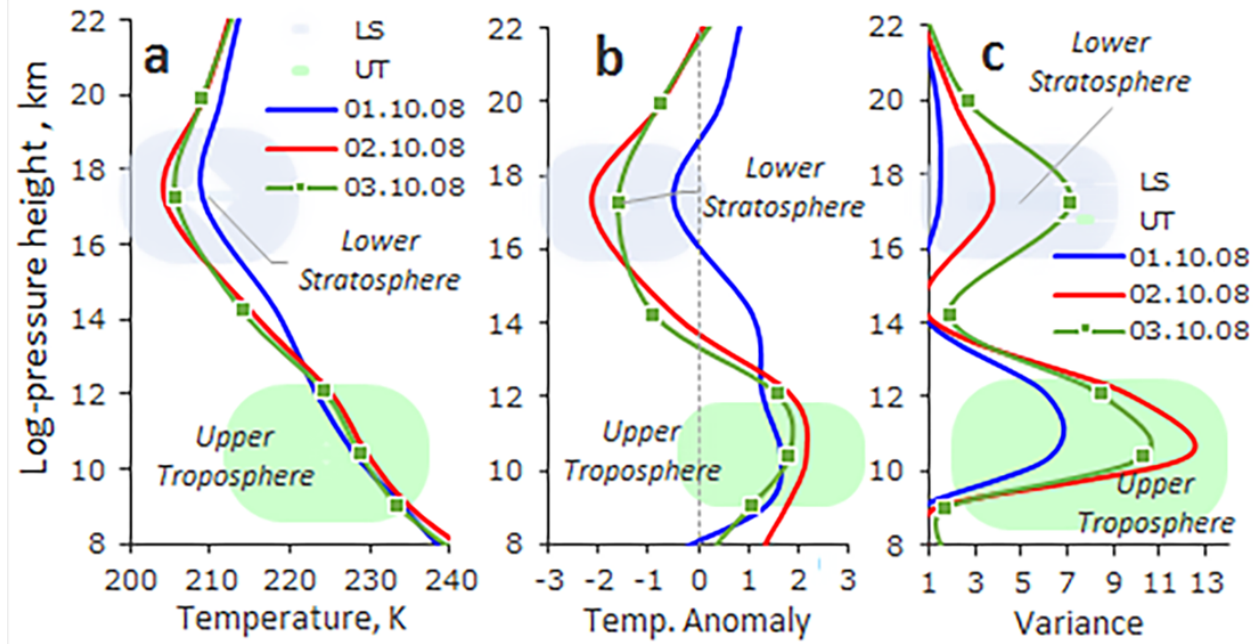

Fig 2. Vertical profiles of temperature (a), normalized anomalies (b) and temperature variances (c) in $8.0-22.0 \mathrm{~km}$ altitude range above the epicentral area $\left(38.5-40.5^{\circ} \mathrm{N} ; 73.125-75.0^{\circ} \mathrm{E}\right)$ of the Nura earthquake of $\mathrm{M}=6.7$ on October 1 through 3, 2008 (00:00 UTC)

\section{Consideration of the results}




\subsection{Identification of perturbations in temperature time series}

The altitude-time section of the $\mathrm{R}=\mathrm{VAR}_{\mathrm{STA}} / \mathrm{VAR}_{\mathrm{LTA}}$ ratio (Fig. 3) demonstrates that before a strong seismic event a consistent change of the UTLS thermal condition due to increase of the amplitude of temperature short-period fluctuations.

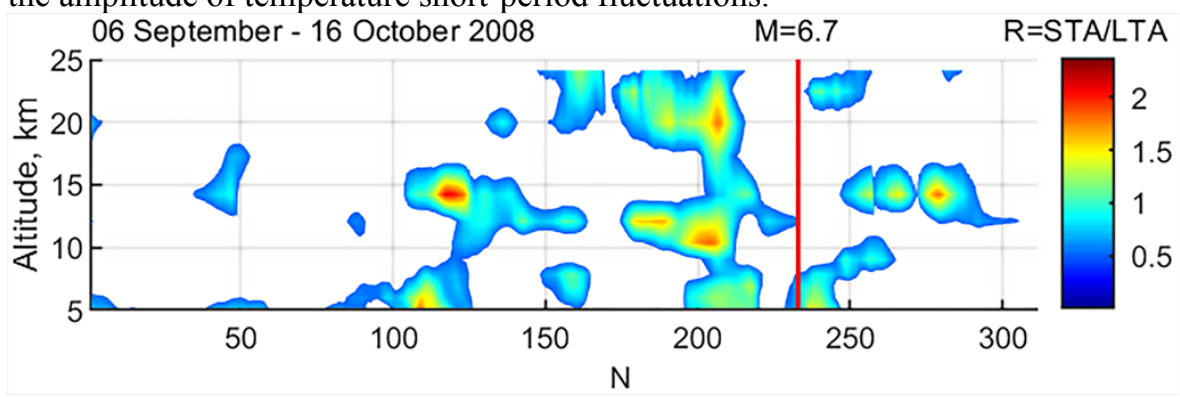

Fig. 3. The altitude-time distribution of the ratio of $\mathrm{R} \geq 0.5$ above the epicentral area of the Nura earthquake during the period of September 06 - October 16, 2008

Fig. 4 displays the process of detection of pre-seismic temperature perturbations (Fig. 4a) during the period of September 1 - October 31, 2008. If a temperature perturbation is detected the VAR $\mathrm{V}_{\mathrm{STA}}$ variance is changing faster than $\operatorname{VAR}_{\mathrm{LTA}}$ (Fig. 4b-4c). Accordingly, a substantial increase of the STA/LTA ratio takes place (Fig. 4d). The algorithm maximally uses the coherence effect in anomalous temperature changes, this was clearly manifested on September 5 and October $2-3,200$. The result revealed windows where parameter $\delta \mathrm{T}$ exceed the threshold vale of $\mathrm{THR}=3.0$ (Fig. 4e). As we can see, the most intensive short-period temperature perturbations in the UTLS domain were observed approximately 2-3 days before the earthquake of $M=6.7$ (Fig. 4f) and they could have been associated with generation of acoustic and gravitational waves [3,4]. At any other time points of the period under investigation this effect was not observed. Processing of satellite data for a longer period (January-December, 2008) demonstrated that an anomalous temperature change going before the main earthquake stuck out against the background of smaller perturbations [5].
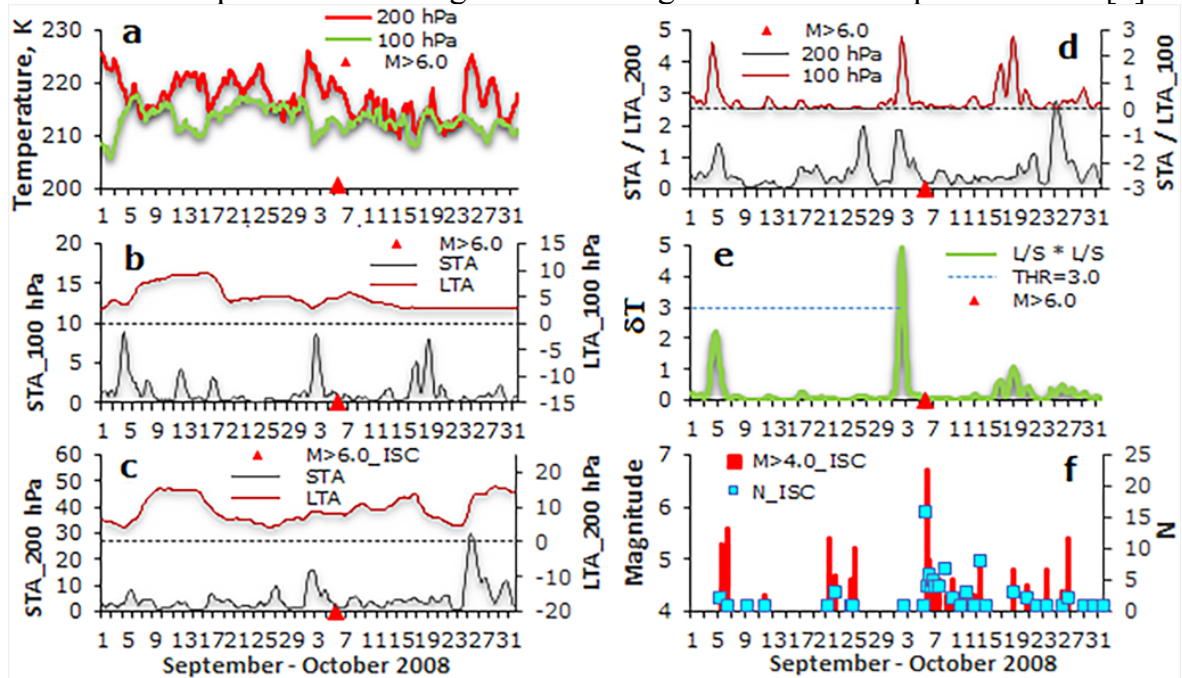

Fig. 4. The initial temperature time series (a); $\mathrm{VAR}_{\mathrm{STA}}$ and $\mathrm{VAR}_{\mathrm{LTA}}$ moving variances at levels of 100 $\mathrm{hPa}(\mathrm{b})$ and $200 \mathrm{hPa}(\mathrm{c})$; corresponding STA/LTA variances ratio (d) and the product thereof ( $\delta \mathrm{T})(\mathrm{e})$ at the point with coordinates $43.0^{\circ} \mathrm{N}$ and $73.125^{\circ} \mathrm{E}$ (markers mark the moment of the earthquake of $\mathrm{M}=6.7$ ); distribution of magnitudes and the number of seismic events (f) during the period of September 1 through October 31, 2008 


\subsection{Spatial-temporal distribution of atmospheric temperature anomalies}

An important component of pre-seismic perturbation is determination of its spatial localization. On the basis of results of the calculations performed the three-dimensional matrix of $\mathrm{dT}_{\mathrm{C}}$ which was used to investigate the dynamics of temperature perturbation distribution in longitudinal and latitudinal directions was restored. The two transversal variability sections of $\delta \mathrm{T}_{\mathrm{C}}$ during the period of September 29 - October 5, 2008 presented in Fig. 5a and Fig. 5b allowed to assess locations and dimensions of anomalous areas, their temporal evolution and to define when $\delta \mathrm{T}_{\mathrm{C}}$ values were maximum.

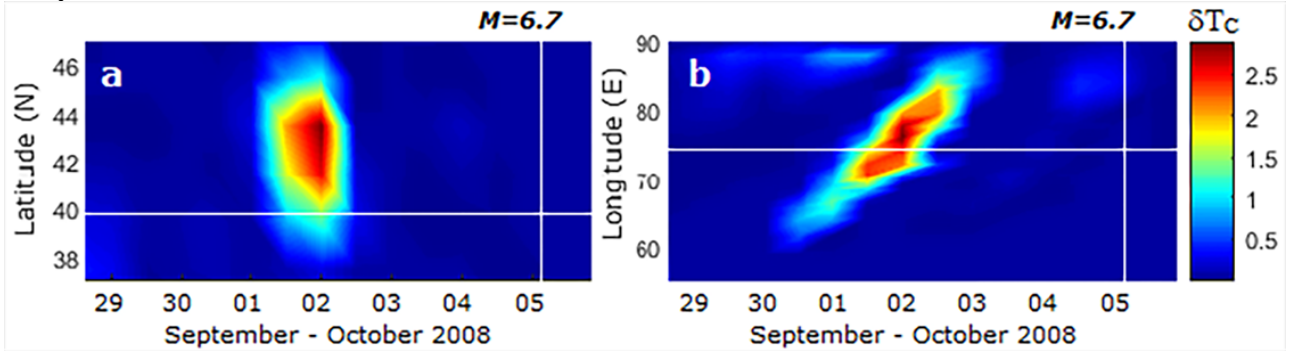

Fig. 5. Distribution of the $\delta \mathrm{T}_{\mathrm{C}}$ parameter by latitude (a) and longitude (b) from September 29 to October 5, 2008. Vertical lines indicate the time of the earthquake (2008-10-05; 15:52:49 UTC). Horizontal lines correspond to coordinates of the earthquake epicenter. Areas where $\delta \mathrm{T}_{\mathrm{C}} \geq \mathrm{THR} \geq 2.0$ are highlighted in red color

The presented figures demonstrate that UTLS perturbations were observed during the period of October 1-3, 2008. The anomalous area started its formation on October 1 at 09:00 UTC west of the epicenter and then it moved along the latitude of $43^{\circ}$ to the east and achieved the maximum on October 2, 2008 three days before the earthquake. The highest values of $\delta \mathrm{T}_{\mathrm{C}}=2.79$ and $\delta \mathrm{T}_{\mathrm{C}}=2.83$ exceeding $\mathrm{THR}=2.0$ were observed at 03:00 and 06:00 UTC accordingly. The mesoscale area of abnormally high values of $\delta \mathrm{T}_{\mathrm{CORR}}$ was located within coordinates of $40-44^{\circ} \mathrm{N}$ and $72-80^{\circ} \mathrm{E}$ (Fig. 6a - Fig. 6d). The maximum of the temperature perturbation observed on October 2, 2008 was displaced by $\sim 2-3^{\circ}$ in the north-westerly direction (at 00:00 UTC) and by $\sim 2-4^{\circ}$ in the north-easterly direction (at 12:00 UTC) in reference to the earthquake epicenter.

The observed effect of anomaly displacement may be associated with air mass horizontal flows predominant in the atmosphere $(\sim 12.0-17.0 \mathrm{~km})$ that were moving at a high speed (above $30 \mathrm{~m} / \mathrm{s}$ ) in the easterly direction (Fig. 6e).
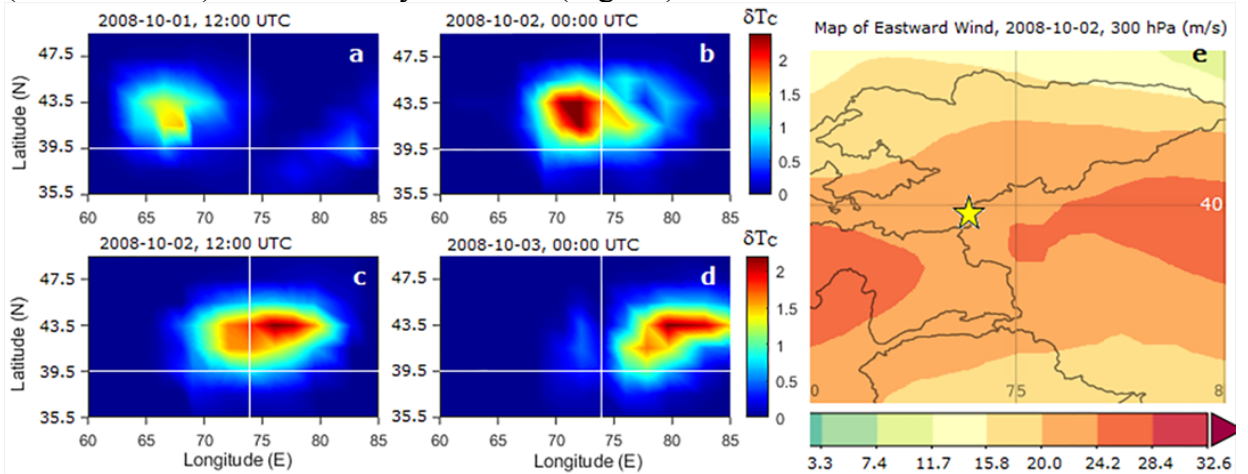

Fig. 6. Evolution of spatial distribution of parameter $\delta \mathrm{T}_{\mathrm{C}}$ during the period of October 1 (12:00 UTC) through October 3, 2008 (00:00 UTC) (a-d). Horizontal and vertical lines correspond to coordinates of the earthquake epicenter of $\mathrm{M}=6.7\left(39.52^{\circ} \mathrm{N} ; 73.77^{\circ} \mathrm{E}\right)$. Map of distribution of eastern component of wind speed at the level of $300 \mathrm{hPa}(00: 00-23: 00 \mathrm{UTC}$, October 2, 2008) (e) 
The quoted results confirm a probable coherence between seismic activity and local temperature perturbation in UTLS that was, steadily observed within 36 hours near the epicenter of the earthquake of $M=6.7$. On the presumption that acoustic-gravity waves (AGW) [3] are the most probable mechanism of perturbation transfer in the lithosphereatmosphere-ionosphere system impact of the tropopause inversion layer on vertical distribution of atmospheric waves is obvious. Energy scattering, local heating and turbulence caused by AGW directly or indirectly change the thermal and dynamic structure of the tropopause area [8, 9] making for formation of perturbations in UTLS [10], that become apparent in temperature short-period anomalous variations.

\section{Conclusion}

Therefore, the presented algorithm based on the use of the modified STA/LTA criterion has sufficient high sensitivity to identify temperature perturbations associated with major earthquakes in the upper troposphere and lower stratosphere. An obvious advantage of the algorithm is simplicity and absence of necessity in additional transformation of initial temperature data.

Effectiveness of the algorithm developed for identification of seismo-atmospheric effects was demonstrated through the example of the Nura earthquake $(\mathrm{M}=6.7)$ in Kyrgyzstan. Algorithm testing results reflect the dynamics of temperature perturbations distinctively associated both in time and in space with the seismic process and preparation period of the earthquake under consideration.

Pre-seismic temperature perturbations in UTLS were identified using the developed algorithm and in some other analyzed instances of strong earthquakes $(M \geq 5.0)$ in the territory of Tien-Shan. However, further study of seismo-atmospheric effects is needed.

Authors enclose gratitude the NASA GES-DISC personnel for providing a free access to satellite measurements data.

The study is partially performed within the framework of the state task of the Federal State Budgetary Institution of Science, Research Station of Russian Academy of Sciences in Bishkek (theme No. AAAA-A19-119020190064-9).

\section{References}

1. V. Tramutoli, R. Corrado, C. Filizzola, N. Genzano, M. Lisi, N. Pergola, Bollettino di Geofisica Teorica ed Applicata, 56, 2, 167 (2015).

2. X. Zhang, C. Kang, W. Ma, J. Ren, Y. Wang, Thermal Science, 22, 2, 767 (2018).

3. S.-S. Yang, T. Asano, M. Hayakawa, J. Geophys. Res.: Space Physics, 124, 2, 1410 (2019).

4. L. Sverdlik, S. Imashev, MAUSAM, 71, 3, 481 (2020).

5. L.G. Sverdlik, Sovremennye problemy distantsionnogo zondirovaniya Zemli iz kosmosa, 18, 3, 141 (2021).

6. URL: https://earthquake.usgs.gov/earthquakes/

7. URL: https://disc.gsfc.nasa.gov/datasets/M2I3NPASM 5.12.4/summary

8. D. Kunkel, P. Hoor, V. Wirth, Geophys. Res. Lett., 41, 7822 (2014).

9. Y. Zhang, S. Zhang, C. Huang, K. Huang, Y. Gong, Q. Gan, J. Geophys. Res. Atmos., 120, 16, 8099 (2015).

10. D. Yu, X. Xu, J. Luo, J. Li, Atmosphere, 10, 2, 75 (2019). 